\title{
The impact of sarcopenia and myosteatosis on postoperative outcomes in patients with inflammatory bowel disease
}

Stephen O'Brien ${ }^{1,2}$, Richard G. Kavanagh ${ }^{3}$, Brian W. Carey ${ }^{3^{*}} \mathbb{D}$, Michael M. Maher ${ }^{3,4}$, Owen J. O'Connor ${ }^{3,4}$ and Emmet J. Andrews ${ }^{2}$

\begin{abstract}
Background: Inflammatory bowel disease (IBD) is a relatively common disorder with significant associated morbidity. Sarcopenia and myosteatosis are associated with adverse postoperative outcomes. This study investigated outcomes in IBD patients undergoing surgical resection relative to the presence of sarcopenia and myosteatosis.

Methods: A retrospective analysis of a prospectively maintained surgical database was conducted. All patients undergoing elective or emergency resection for IBD between 2011 and 2016, with a contemporaneous perioperative computed tomography (CT) scan, were included. Patient demographics, clinical and biochemical measurements were collected. Skeletal muscle index and attenuation were measured on perioperative CT scans using Osirix version 5.6.1. Univariate and multivariate regression analysis was used to identify risk factors for adverse postoperative outcomes.

Results: Seventy-seven patients (46 male, 31 female; mean age 42 years, range 20-80 years) were included. Thirty patients (30\%) had sarcopenia and 26 (34\%) had myosteatosis. Myosteatosis was significantly associated with increased hospital stay postoperatively ( 9 versus 13 days). Sarcopenia and myosteatosis were associated with hospital readmission within 30 days on univariate analysis. Multivariate regression analysis demonstrated an independent association between myosteatosis and hospital readmission. Sixteen patients (21\%) had a clinically relevant postoperative complication, but an association with sarcopenia and myosteatosis was not observed. A neutrophil-lymphocyte ratio greater than 5 was predictive of clinically relevant postoperative complications on multivariate regression analysis.
\end{abstract}

Conclusions: Myosteatosis was associated with increased hospital stay and increased 30-day hospital readmission rates on multivariate regression analysis. Sarcopenia and myosteatosis in IBD were not associated with clinically relevant postoperative complications.

Keywords: Inflammatory bowel diseases, Sarcopenia, Muscle (skeletal), Morbidity, Length of stay, Tomography (x-ray, computed)

\section{Key points}

- Myosteatosis was associated with increased hospital stay and increased 30-day hospital readmission rates for patients who suffer from IBD requiring resection surgery

- The considerations of sarcopenia and myosteatosis as potential modifiable risk factors for adverse postoperative outcomes in patients who suffer

\footnotetext{
* Correspondence: brian_carey@ucc.ie

${ }^{3}$ Department of Radiology, Cork University Hospital, Cork, Ireland

Full list of author information is available at the end of the article
}

from IBD requiring resection surgery merits further research

\section{Background \\ Inflammatory bowel disease (IBD) is a relatively com- mon chronic inflammatory disorder of the gastrointes- tinal tract. Ulcerative colitis and Crohn disease are the principal subtypes. The incidence in Northern Europe is 6.3 per 100,000 person years for Crohn disease and 11.4 for ulcerative colitis $[1,2]$. IBD has a complex pathophysiology consisting of an interaction between}


genetic susceptibility, the environment and the host immune responses.

Clinical differentiation between subtypes is essential with regard to management decisions. Up to $80 \%$ of patients with Crohn disease will require surgery in their lifetime and surgery is both an emergency and definitive therapy for ulcerative colitis [2,3]. Up to $30 \%$ of patients with ulcerative colitis will require colectomy [2]. These patients suffer significant nutritional challenges associated with their pathology as a result of malabsorptive and chronic inflammatory states.

The incidence of postoperative complications in patients with IBD undergoing resection surgery ranges from 20 to $40 \%$ [4-6]. Morbidity associated with IBD may be partly attested to by the characteristics of the typical preoperative IBD patient: poor nutritional status, preoperative sepsis (localised or systemic) or intestinal obstruction. Often these patients will require a number of investigations in an attempt to delineate disease severity, disease activity, and the presence of complications in order to determine optimal management. Computed tomography (CT) is frequently used for this purpose [7]. CT can also be used to provide additional information pertaining to patients' general health, including muscle volume and attenuation.

Sarcopenia has been defined by the European Working Group on Sarcopenia in Older People (EWGSOP) as a low muscle mass and either decreased muscle strength or low physical performance [8]. Interest in the role of sarcopenia in surgical patients has grown in the last number of years, especially in the field of oncology. A number of recent studies have demonstrated an adverse association between sarcopenia and immediate and long-term patient outcomes following surgery including postoperative complications, length of hospital stay, recurrence-free, and overall survival [9-11]. Myosteatosis is the process of infiltration of lipid into both the inter- and intra-muscular compartments and, similarly to sarcopenia, has been associated with worse outcomes in both oncological and non-oncological patients $[12,13]$.

Previous studies have examined the role of body fat analysis in association with outcomes of IBD patients but few studies examining the role of muscle mass and muscle quality have been conducted [14-16]. The aim of this study was to investigate sarcopenia and myosteatosis with respect to postoperative outcomes in patients undergoing surgical resection for IBD.

\section{Methods}

\section{Patients}

This study was conducted in accordance with STrengthening the Reporting of OBservational studies in Epidemiology (STROBE) guidelines [17]. Ethical approval was granted by the hospital Institutional Research Ethics
Review Board. All consecutive patients who underwent a colonic resection for IBD, between 2009 and 2016 in a tertiary referral colorectal surgery service, were retrospectively identified from a prospectively maintained database. Patient medical records were analysed to obtain baseline demographics, including diagnosis, body mass index (BMI), presence of comorbidities (scored according to the American Society of Anesthesiologist [ASA]), preoperative medications, and smoking status. The Charlson Comorbidity Index (CCI) [18], which is predictive of 10-year survival and the neutrophil-lymphocyte ratio (NLR) were calculated for all patients. Perioperative haematological and biochemical levels were recorded. All surgeries were carried out by a single colorectal surgeon specialised in IBD treatment. The type of abdominal access and extent of surgical resection were documented from the operative note. Postoperative complications were graded according to the Clavien-Dindo classification system [19]. Intra-abdominal leaks were classified on the basis of their management [20]. A leak requiring action by surgery or interventional radiology was classified as clinically relevant.

\section{CT protocol, scan selection and image analysis}

The hospital information technology system was searched for perioperative CT of the abdomen and pelvis in these patients. CT scans within 6 months prior to surgery or in the first postoperative month were selected. All patients underwent a CT scan of the abdomen and pelvis with a standardised protocol using the following parameters: scan range encompassing the lung bases to the pubic symphysis; $0.625-\mathrm{mm}$ slice acquisition thickness; intravenously administered contrast (Iohexol, Omnipaque 300, GE Healthcare, Waukesha, WI, USA) delivered at $2.5 \mathrm{~mL} / \mathrm{s}$ and imaged in the portal venous phase; $1.5 \mathrm{~L}$ of positive oral contrast (2\% Gastrografin, Bracco Diagnostics Inc., Princeton, NJ, USA); tube voltage of $120 \mathrm{kVp}$; automated tube current modulation resulting in a variable current with a minimum of $50 \mathrm{~mA}$ and a maximum of $350 \mathrm{~mA}$; gantry rotation time of $0.8 \mathrm{~s}$; noise index 38. All CT images were acquired using a single 64-slice multi-detector row CT scanner (General Electric Lightspeed VCT-XTe, GE Healthcare, GE Medical Systems, Waukesha, WI, USA).

Preoperative scans were preferentially selected. When these were unavailable, the earliest postoperative scans were used. The CT scans were analysed using Osirix version 5.6.1 open source software (32-bit; http:// www.osirix-viewer.com).

The cross-sectional skeletal muscle area $\left(\mathrm{cm}^{3}\right)$ was measured, as previously described [11, 21]. Briefly, two sequential scans at the level of the third lumbar vertebra, in which both transverse processes were visible, were selected. The grow/regrow tool was used to measure the skeletal muscle area on these axial slices by a reviewer 
blinded to the patients' demographics. The skeletal muscles included were the psoas, paraspinal and abdominal wall muscles. The threshold range for skeletal muscle was from -30 to +150 Hounsfield Units (HU) [22, 23].

The average muscle mass area of these two slices was used. The skeletal muscle area was normalised for height to produce the skeletal muscle index [24]. The specific cutoff values used for declaring a patient to be affected with sarcopenia were $<41 \mathrm{~cm}^{2} / \mathrm{m}^{2}$ in women, $<43 \mathrm{~cm}^{2} /$ $\mathrm{m}^{2}$ in men with a BMI $<25 \mathrm{~kg} / \mathrm{m}^{2}$, and $<53 \mathrm{~cm}^{2} / \mathrm{m}^{2}$ in men with a $B M I \geq 25 \mathrm{~kg} / \mathrm{m}^{2}$, as published by Martin et al. [11]. The cutoff values for myosteatosis were $<41 \mathrm{HU}$ in men or women with a BMI $<25 \mathrm{~kg} / \mathrm{m}^{2}$ and $<33 \mathrm{HU}$ in men or women with a BMI $\geq 25 \mathrm{~kg} / \mathrm{m}^{2}$ [12]. An example of the methods employed for image analysis is demonstrated in Fig. 1.

\section{Statistical analysis}

Statistical analysis was carried out using SPSS v20.0 software (SPSS Inc., Chicago, IL, USA). Normality was assessed using the Kolmogorov-Smirnov test. The independent $t$ test and Mann-Whitney $U$ test were used to compare continuous variables. The $\chi^{2}$ and Fischer's exact tests were used to compare categorical variables. The impact of sarcopenia and myosteatosis was analysed by univariate regression analysis. A $p$ value lower than 0.05 was used as the level of significance.

\section{Results}

Ninety-six patients who had had surgery for IBD over the specified time period were identified from the database but 19 patients were excluded due to the lack of a suitable CT scan. These 77 patients were included in the study, 46 of them being male. Patient demographics, clinical indices, disease location/behaviour and pathological data are summarised in Table 1 .

Of the 77 included patients, $30(39 \%)$ were shown to be affected by sarcopenia and 26 (34\%) by myosteatosis. Of the 52 patients (68\%) diagnosed with Crohn disease, 22 had sarcopenia, 30 did not. Of the 21 patients (27\%) diagnosed with ulcerative colitis, 6 had sarcopenia and 15 did not. There were $4 / 77$ patients (5\%) with a diagnosis of indeterminate colitis, of whom two had sarcopenia and two did not.

Stratification of patients based on the presence or absence of sarcopenia demonstrated that only patient weight and BMI were statistically different between the groups; patients with sarcopenia had a lower weight and BMI ( $p=0.013$ and $p=0.025$, respectively). There was no difference in patient comorbidity profiles, as assessed by the ASA and CCI scores $(p=0.681$ and $p=0.214)$. Of the 77 patients, $42(55 \%)$ received preoperative steroid therapy and 34 patients (44\%) had been receiving immunosuppressive therapy prior to surgery. While

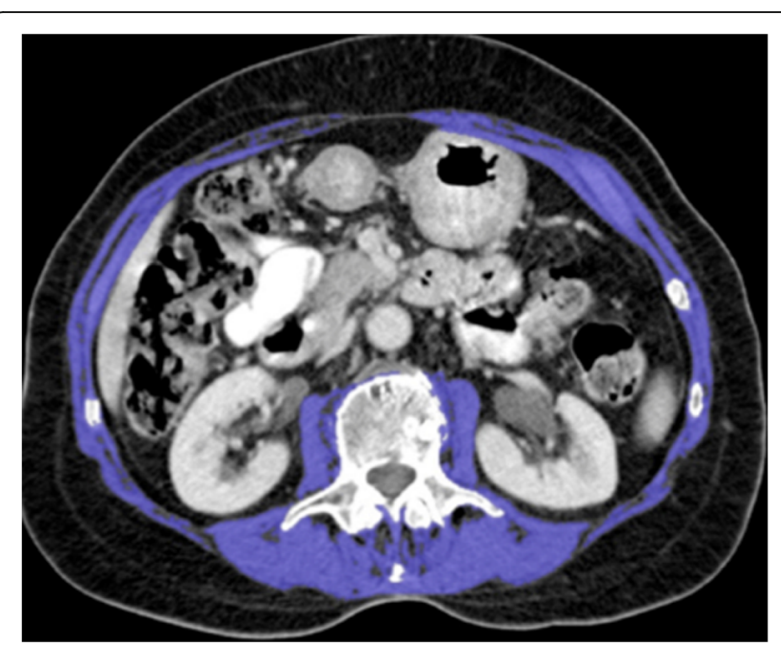

Fig. 1 Example of computed tomography $(C T)$ image analysis methods on Osirix version 5.6.1 open source software

markers of inflammation, including the mean white cell count and C- reactive protein, were elevated, there was no difference between the groups $(p=0.500$ and $p=$ 0.252 , respectively). Neither was a difference observed in white cell titres or haemoglobin levels.

Surgical details, including indications for surgery, are summarised in Table 2. No patients had perianal disease. Sixty percent of patients had emergency surgery. No difference was demonstrated between the patients with sarcopenia and those without in relation to the extent of surgical resection. Patient outcomes stratified by the presence of sarcopenia are presented in Table 3.

The median length of hospital stay was 10 days (interquartile range 8-15). There was no significant difference in median length of hospital admission between patients with sarcopenia and those without (10 days versus 10 days, $p=0.741$ ). There was a significant difference in the length of hospital stay between patients with myosteatosis and those without (13 days versus 9 days, $p=$ 0.039). Table 4 stratifies the outcomes by the presence of myosteatosis.

Of 77 patients, 10 (14\%) required hospital readmission within 30 days of surgery. There was a statistically significant difference in the number of hospital readmissions between the sarcopenia and the non-sarcopenia groups $(p=0.030)$. Patients with myosteatosis also required readmission more frequently $(p=0.011)$.

As sarcopenia and myosteatosis were associated with hospital readmission, we further analysed the strength of this finding. Univariate and multivariate regression analysis was used to identify factors associated with hospital readmissions (Table 4). Sarcopenia and myosteatosis were significant risk factors for readmission on univariate analysis (odds ratio $[\mathrm{OR}]=4.778, p=0.034$ and $\mathrm{OR}=$ $6.451, p=0.012$, respectively). Only the presence of 
Table 1 Clinical indices and pathological data of patients stratified by the presence of preoperative sarcopenia

\begin{tabular}{|c|c|c|c|c|}
\hline & $\begin{array}{l}\text { All patients }(n=77) \\
n(\%)\end{array}$ & $\begin{array}{l}\text { No sarcopenia }(n=47) \\
n(\%)\end{array}$ & $\begin{array}{l}\text { Sarcopenia }(n=30) \\
n(\%)\end{array}$ & $p$-value \\
\hline Age, years (range) & $42(20-80)$ & $41(21-74)$ & $43(20-80)$ & $0.538^{\mathrm{a}}$ \\
\hline \multicolumn{5}{|l|}{ Gender } \\
\hline Male & $46(60)$ & $31(66)$ & $15(50)$ & \multirow[t]{2}{*}{$0.124^{b}$} \\
\hline Female & $31(40)$ & $16(34)$ & $15(50)$ & \\
\hline \multicolumn{5}{|l|}{ Diagnosis } \\
\hline Ulcerative colitis & $21(27)$ & $15(32)$ & $6(20)$ & \multirow[t]{3}{*}{$0.504^{c}$} \\
\hline Crohn disease & $52(68)$ & $30(64)$ & $22(73)$ & \\
\hline Indeterminate colitis & $4(5)$ & $2(4)$ & $2(7)$ & \\
\hline \multicolumn{5}{|l|}{ Location (Crohn) } \\
\hline$L 1$, ileal & $14(27)$ & $9(30)$ & $5(23)$ & \multirow[t]{3}{*}{0.443} \\
\hline L2, colonic & $37(71)$ & $21(70)$ & $16(73)$ & \\
\hline L3, ileocolonic & $1(2)$ & $0(0)$ & 1 (4) & \\
\hline \multicolumn{5}{|l|}{ Behaviour (Crohn) } \\
\hline B1, non-stricturing, non-penetrating & $11(21)$ & $6(20)$ & $5(23)$ & \multirow[t]{4}{*}{0.047} \\
\hline B2, stricturing & $19(37)$ & $15(50)$ & $4(18)$ & \\
\hline B3, penetrating & $22(42)$ & $9(30)$ & $13(59)$ & \\
\hline$P$, perianal disease & $0(0)$ & $0(0)$ & $0(0)$ & \\
\hline Body weight, kg (range) & $73(32-129)$ & $76(53-118)$ & $70(32-129)$ & $0.170^{a}$ \\
\hline BMI, median (range) & $24(16-37)$ & $24(19-33)$ & $21(16-37)$ & $0.037^{d}$ \\
\hline \multicolumn{5}{|l|}{ BMI categories } \\
\hline Underweight & $5(7)$ & $0(0)$ & $5(17)$ & \multirow[t]{4}{*}{$0.028^{c}$} \\
\hline Normal & $44(57)$ & $28(60)$ & $16(53)$ & \\
\hline Overweight & $12(16)$ & $8(19)$ & $3(10)$ & \\
\hline Obese & $16(21)$ & $10(21)$ & $6(20)$ & \\
\hline \multicolumn{5}{|l|}{ ASA physical score } \\
\hline Grade 1 & $13(17)$ & $9(19)$ & $4(13)$ & \multirow[t]{4}{*}{$0.681^{c}$} \\
\hline Grade 2 & $49(64)$ & $30(64)$ & $19(63)$ & \\
\hline Grade 3 & $14(18)$ & $8(17)$ & $6(20)$ & \\
\hline Grade 4 & $1(1)$ & $0(0)$ & 1 (3) & \\
\hline \multicolumn{5}{|l|}{ Charlson Comorbidity Index } \\
\hline 0 & $35(45)$ & $20(43)$ & $15(50)$ & \multirow[t]{8}{*}{$0.214^{c}$} \\
\hline 1 & $20(26)$ & $15(32)$ & $5(17)$ & \\
\hline 2 & $11(14)$ & $5(11)$ & $6(20)$ & \\
\hline 3 & $3(39)$ & $3(6)$ & $0(0)$ & \\
\hline 4 & $2(26)$ & $0(0)$ & $2(7)$ & \\
\hline 5 & $4(52)$ & $2(4)$ & $2(7)$ & \\
\hline 6 & $1(1)$ & 1 (2) & $0(0)$ & \\
\hline 7 & $1(1)$ & $1(2)$ & $0(0)$ & \\
\hline \multicolumn{5}{|l|}{ Smoking status } \\
\hline Non-smoker & $49(64)$ & $29(62)$ & $20(67)$ & \multirow[t]{3}{*}{$0.558^{b}$} \\
\hline Ex-smoker & $15(19)$ & $11(23)$ & $4(13)$ & \\
\hline Smoker & $13(17)$ & $7(15)$ & $6(20)$ & \\
\hline
\end{tabular}


Table 1 Clinical indices and pathological data of patients stratified by the presence of preoperative sarcopenia (Continued)

\begin{tabular}{|c|c|c|c|c|}
\hline & $\begin{array}{l}\text { All patients }(n=77) \\
n(\%)\end{array}$ & $\begin{array}{l}\text { No sarcopenia }(n=47) \\
n(\%)\end{array}$ & $\begin{array}{l}\text { Sarcopenia }(n=30) \\
n(\%)\end{array}$ & $p$-value \\
\hline No & $35(46)$ & $22(47)$ & $13(43)$ & $0.475^{\mathrm{b}}$ \\
\hline Yes & $42(55)$ & $25(53)$ & $17(57)$ & \\
\hline \multicolumn{5}{|l|}{ Preoperative immunosuppression } \\
\hline No & $43(56)$ & $23(49)$ & $20(67)$ & $0.098^{b}$ \\
\hline Yes & $34(44)$ & $24(51)$ & $10(33)$ & \\
\hline \multicolumn{5}{|l|}{ Preoperative anticoagulation } \\
\hline No & $73(95)$ & $45(96)$ & $28(93)$ & $0.509^{c}$ \\
\hline Yes & $4(5)$ & $2(4)$ & $2(7)$ & \\
\hline Haemoglobin, male (range) & $12(10.5-13.6)$ & $12.6(10.5-13.7)$ & $11.6(10.3-12.3)$ & 0.122 \\
\hline Haemoglobin, female (range) & $11.6(10.5-13.6)$ & $12.8(11.4-13.8)$ & $11.0(9.8-12)$ & 0.024 \\
\hline White cell count (cells $\times 10^{9} / \mathrm{L}$ ) & $10.63(3.7-28.1)$ & $10.88(5.1-28.1)$ & $10.26(3.7-19.6)$ & $0.500^{d}$ \\
\hline Neutrophil-lymphocyte ratio & $7.1(1.09-26.81)$ & $6.77(1.09-22.65)$ & $8.02(1.11-26.81)$ & $0.901^{d}$ \\
\hline Albumin (g/L) & $34.9(17-51)$ & $35.28(20-48)$ & $33.52(17-51)$ & $0.283^{d}$ \\
\hline C-reactive protein (mg/L) & $53.04(0-547)$ & $46.16(0-374.7)$ & $63.26(0-547)$ & $0.252^{d}$ \\
\hline
\end{tabular}

$B M I$ Body Mass Index, ASA American Society of Anesthesiologists

${ }^{\mathrm{a}}$ Independent $t$ test, ${ }^{\mathrm{b}} \mathrm{X}^{2}$ test, ${ }^{\mathrm{c}}$ Fischer's exact test, ${ }^{\mathrm{d}}$ Mann-Whitney $U$ test

myosteatosis remained statistically significant on multivariate regression analysis $(\mathrm{OR}=4.802, \quad p=0.043)$ (Table 5).

Of the 77 patients, 16 (21\%) had a Clavien-Dindo complication score greater or equal to 3 a (postoperative complication treated with intervention not requiring general anaesthesia), and 11 (14\%) had an intra-abdominal leak requiring treatment with surgery or interventional radiology. Univariate and multivariate regression analysis were used to identify risk factors associated with significant hospital complications (Clavien-Dindo score $\geq$ 3a) (Table 6). On univariate analysis, age greater than 65 years, $\mathrm{CCI} \geq 3$ and NLR $>5$ were significant risk factors for complications $(\mathrm{OR}=6.444, p=0.024$, $\mathrm{OR}=4.167, p$ $=0.039$ and $\mathrm{OR}=4.320, p=0.021)$. Only the presence of a NLR > 5 remained statistically significant on multivariate regression analysis $(\mathrm{OR}=4.489, p=0.024)$.

\section{Discussion}

This study assessed postoperative outcomes, including length of admission, readmission rates and serious complications, in a cohort of patients with IBD undergoing resection surgery, stratifying patients based on the presence of sarcopenia and myosteatosis. The results add to existing evidence indicating that patients who suffer from IBD requiring resection surgery who also have perioperative sarcopenia, and in particular myosteatosis, require increased postoperative care. The importance of myosteatosis in relation to postoperative outcomes is gaining increasing recognition [25] and this study provides new evidence in this regard.
These findings may form the basis for further assessment of the timing of surgery in such patients, taking into consideration the influence of pre- and postoperative nutritional status. In fact, many of the surgeries in IBD patients are performed as emergencies and offer little potential to optimise nutritional status prior to surgery. Nevertheless, patients with myosteatosis, despite spending longer in hospital, were also more likely to require readmission.

It has been previously demonstrated that hospitalised patients with IBD have a greater protein-calorie deficiency compared with non-IBD patients [26]. Investigation of methods for improving the nutritional and functional status of IBD patients prior to discharge following resection surgery, or also efforts on an outpatient basis, would help reduce readmission rates. Increased home visits or earlier review at outpatient clinics could work in this direction.

Patient selection is a potential confounding factor. However, the incidence of sarcopenia and postoperative complications in the present study were within expected limits. For example, the incidence of sarcopenia in patients with IBD has been reported to range from 26 to $60 \%$ [27-29]. The incidence of sarcopenia in the present cohort was $39 \%$ and, therefore, within this range.

On the other side, patients with ulcerative colitis were reported to have a lower incidence of sarcopenia when compared with those with those with Crohn disease [30], a difference which could potentially affect outcomes. However, patients with Crohn disease accounted for the greater proportion of patients in the present paper. 
Table 2 Operative details stratified by sarcopenia

\begin{tabular}{|c|c|c|c|c|}
\hline & $\begin{array}{l}\text { All patients } \\
(n=77) \\
n(\%)\end{array}$ & $\begin{array}{l}\text { No sarcopenia } \\
(n=47) \\
n(\%)\end{array}$ & $\begin{array}{l}\text { Sarcopenia } \\
(n=30) \\
n(\%)\end{array}$ & $p$-value \\
\hline \multicolumn{5}{|l|}{ Elective surgery } \\
\hline Yes & $31(40)$ & $19(40)$ & $12(40)$ & \multirow[t]{2}{*}{$0.581^{a}$} \\
\hline No & $46(60)$ & $28(60)$ & $18(60)$ & \\
\hline \multicolumn{5}{|l|}{ Indication for surgery } \\
\hline Stage 2 surgery for IPPA & $6(8)$ & $3(6)$ & $2(7)$ & \multirow[t]{5}{*}{0.850} \\
\hline Stricture & $19(24)$ & $13(28)$ & $6(20)$ & \\
\hline Fistula & $9(12)$ & $6(13)$ & $4(13)$ & \\
\hline Medically refractory disease & $33(43)$ & $18(38)$ & $15(50)$ & \\
\hline Perforation & $10(13)$ & $7(15)$ & $3(10)$ & \\
\hline \multicolumn{5}{|l|}{ Type of surgery } \\
\hline Open & $18(23)$ & $7(15)$ & $11(37)$ & \multirow[t]{4}{*}{$0.153^{b}$} \\
\hline Laparoscopic & $52(68)$ & $35(75)$ & $17(57)$ & \\
\hline Laparoscopic-assisted & $3(4)$ & $2(4)$ & $1(3)$ & \\
\hline Open $\rightarrow$ laparoscopic & $4(5)$ & $3(6)$ & $1(3)$ & \\
\hline \multicolumn{5}{|l|}{ Extent of surgery } \\
\hline Completion proctectomy, ileal pouch anal anastomosis and end-ileostomy & $5(7)$ & $3(6)$ & $2(7)$ & \multirow[t]{11}{*}{$0.557^{b}$} \\
\hline Panproctocolectomy and end-ileostomy & $6(8)$ & $3(6)$ & $3(10)$ & \\
\hline Sigmoid colectomy & $6(8)$ & $5(11)$ & $1(3)$ & \\
\hline lleocecectomy & $14(18)$ & $9(19)$ & $5(17)$ & \\
\hline Anastomosis revision & $1(1)$ & $1(2)$ & $0(0)$ & \\
\hline Right hemicolectomy & $11(14)$ & $8(17)$ & $3(10)$ & \\
\hline Subtotal colectomy and end-ileostomy & $27(35)$ & $15(32)$ & $12(40)$ & \\
\hline Left hemicolectomy and defunctioning loop ileostomy & $1(1)$ & $1(2)$ & $0(0)$ & \\
\hline Completion proctectomy and end-ileostomy & $3(4)$ & $1(2)$ & $2(7)$ & \\
\hline Ileorectal anastomosis & $2(3)$ & $0(0)$ & $2(7)$ & \\
\hline Anterior resection and end-colostomy & $1(1)$ & $1(1)$ & $0(0)$ & \\
\hline
\end{tabular}

Elective surgery = planned hospital admission for surgery, non-elective surgery = non-planned surgical intervention. IPPA ileal pouch anal anastomosis ${ }^{a} x^{2}$ test, ${ }^{b}$ Fischer's exact test

Almost $60 \%$ of patients in the present study underwent emergency surgery, which would have the potential to increase complication rates. The incidence of postoperative complications in the present paper was $21 \%$, which was also within expected practice as complication rates of up to $27 \%$ have been reported in IBD patients [6]. A recent study by Pederson et al. [31] reported a similar incidence of Clavien-Dindo type-3a complications (25\%) and similar length of hospital admission (8 days) compared with the present study. Six patients $(8 \%)$ required reoperation in the present study, which is again comparable with published data $[4,5,31]$.

The present study demonstrated no significant difference in the incidence of type-3a or greater Clavien-Dindo

Table 3 Analysis of hospital outcomes by sarcopenia

\begin{tabular}{|c|c|c|c|c|}
\hline & $\begin{array}{l}\text { All patients }(n=77) \\
n(\%)\end{array}$ & $\begin{array}{l}\text { No sarcopenia }(n=47) \\
n \%\end{array}$ & $\begin{array}{l}\text { Sarcopenia }(n=30) \\
n \%\end{array}$ & $p$-value \\
\hline Major complication (Clavien-Dindo $\geq 3 a)$ & $16(21)$ & $10(21)$ & $6 \quad(20)$ & $0.566^{\mathrm{a}}$ \\
\hline Major intra-abdominal leak & $11(14)$ & $7(15)$ & $4 \quad(13)$ & $0.564^{c}$ \\
\hline Length of hospital admission (days) median (IQR) & $10(8-15)$ & $10(8-14)$ & $10.5(7-18)$ & $0.741^{b}$ \\
\hline Hospital readmission $<30$ days & $10(14)$ & $3(6)$ & $7 \quad(23)$ & $0.030^{c}$ \\
\hline
\end{tabular}


Table 4 Analysis of hospital outcomes by myosteatosis

\begin{tabular}{|c|c|c|c|c|}
\hline & $\begin{array}{l}\text { All patients }(n=77) \\
n(\%)\end{array}$ & $\begin{array}{l}\text { No myosteatosis }(n=51) \\
n(\%)\end{array}$ & $\begin{array}{l}\text { Myosteatosis }(n=26) \\
n(\%)\end{array}$ & $p$-value \\
\hline Major complication (Clavien-Dindo $\geq 3 \mathrm{a}$ ) & $16(21)$ & $9(18)$ & $7(27)$ & $0.254^{a}$ \\
\hline Major intra-abdominal leak & $11(14)$ & $5(10)$ & $6(23)$ & $0.111^{\mathrm{a}}$ \\
\hline Length of hospital admission, days (median, IQR) & $10(8-15)$ & $10(7-13)$ & $13(9-24)$ & $0.039^{b}$ \\
\hline Hospital readmission $<30$ days & $10(13)$ & $3(6)$ & $7(27)$ & $0.011^{c}$ \\
\hline
\end{tabular}

IQR interquartile range

${ }^{a} X^{2}$ test, ${ }^{b}$ Mann-Whitney $U$ test, ${ }^{c}$ Fischer's exact test

complications between sarcopenia and non-sarcopenia patient groups. Other studies reported differed data in this regard. Zhang et al. [28] found a decreased incidence of complications in non-sarcopenia patients (2.3 compared with $15.7 \%)$. However, when comparing this data with our results, we should consider that the patients were ten years younger, the definition of sarcopenia was slightly different, and the prevalence of sarcopenia was more than double.

Patients with IBD are prone to preoperative sarcopenia and myosteatosis due to a combination of chronic illness, abdominal pain hindering oral intake, malabsorption and the effects of medications [32]. In addition, disease activity and the pro-inflammatory state of IBD patients was perioperatively attested to in the present study by the increased incidence of clinically relevant complications with a NLR greater than five. This has been noted previously in the setting of colorectal carcinoma [33]. The treatment of postoperative leaks is very challenging in IBD patients due to the frequent presence of a hostile abdominal status, resulting in a preference for non-surgical drainage by interventional radiology approaches [34].

Table 5 Univariate and multivariate regression analysis for risk factors of readmission

\begin{tabular}{|c|c|c|c|c|c|c|}
\hline & \multicolumn{3}{|c|}{ Univariate analysis } & \multicolumn{3}{|c|}{ Multivariate analysis } \\
\hline & OR & $95 \% \mathrm{Cl}$ & $p$-value & OR & $95 \% \mathrm{Cl}$ & $p$-value \\
\hline$\overline{\text { Age }}$ & 0.989 & $0.943-1.037$ & 0.647 & & & \\
\hline Gender (male) & 1.462 & $0.384-5.560$ & 0.578 & & & \\
\hline \multicolumn{7}{|l|}{ Diagnosis } \\
\hline Ulcerative colitis & 1 & & 1 & & & \\
\hline Crohn & 1 & $0.232-4.310$ & 0.999 & & & \\
\hline Indeterminate colitis & 0.00 & 0.00 -infinity & 0.000 & & & \\
\hline \multicolumn{7}{|l|}{ BMI category } \\
\hline Underweight & 1 & & & & & \\
\hline Normal & 0.848 & $0.082-8.792$ & 0.890 & & & \\
\hline Overweight & 0.000 & 0.00 -infinity & 0.999 & & & \\
\hline Obese & 0.615 & $0.044-8.703$ & 0.719 & & & \\
\hline ASA physical score $\geq 3$ & 0.000 & 0.000 -infinity & 0.999 & & & \\
\hline Charlson Comorbidity Index $\geq 3$ & 0.905 & $0.099-8.248$ & 0.929 & & & \\
\hline \multicolumn{7}{|l|}{ Smoking status } \\
\hline Non-smoker & 1 & & & & & \\
\hline Ex-smoker & 2.150 & $0.448-10.312$ & 0.339 & & & \\
\hline Smoker & 1.911 & $0.319-11.450$ & 0.478 & & & \\
\hline Neutrophil-lymphocyte ratio $>5$ & 1.929 & $0.496-7.5$ & 0.343 & & & \\
\hline Albumin $>35 \mathrm{~g} / \mathrm{L}$ & 0.606 & $0.156-2.357$ & 0.606 & & & \\
\hline Preoperative steroid use & 3.758 & $0.740-19.086$ & 0.110 & & & \\
\hline Preoperative immunosuppression & 0.756 & $0.194-2.935$ & 0.686 & & & \\
\hline Emergency surgery & 1.703 & $0.403-7.191$ & 0.469 & & & \\
\hline Sarcopenia & 4.778 & $1.121-20.361$ & 0.034 & 3.251 & $0.707-14.951$ & 0.130 \\
\hline Myosteatosis & 6.451 & $1.495-27.829$ & 0.012 & 4.802 & $1.053-21.889$ & 0.043 \\
\hline
\end{tabular}


Table 6 Univariate and multivariate regression analysis for risk factors of major complication

\begin{tabular}{|c|c|c|c|c|c|c|}
\hline & \multicolumn{3}{|c|}{ Univariate analysis } & \multicolumn{3}{|c|}{ Multivariate analysis } \\
\hline & OR & $95 \% \mathrm{Cl}$ & $p$-value & OR & $95 \% \mathrm{Cl}$ & $p$-value \\
\hline Age $>65$ years & 6.444 & $1.274-32.593$ & 0.020 & 4.274 & $0.242-75.356$ & 0.321 \\
\hline Gender (male) & 0.420 & $0.122-1.449$ & 0.170 & & & \\
\hline \multicolumn{7}{|l|}{ Diagnosis } \\
\hline Ulcerative colitis & 1 & & & & & \\
\hline Crohn & 3.167 & $0.648-15.474$ & 0.154 & & & \\
\hline Indeterminate colitis & 3.167 & $0.215-46.726$ & 0.401 & & & \\
\hline \multicolumn{7}{|l|}{ BMI category } \\
\hline Underweight & 1 & & 0.631 & & & \\
\hline Normal & 0.435 & $0.063-3.021$ & 0.400 & & & \\
\hline Overweight & 0.375 & $0.035-3.999$ & 0.417 & & & \\
\hline Obese & 0.214 & $0.021-2.187$ & 0.194 & & & \\
\hline ASA physical score $\geq 3$ & 2.318 & $0.660-8.138$ & 0.189 & & & \\
\hline Charlson Comorbidity index $\geq 3$ & 4.167 & $1.078-16.103$ & 0.039 & 1.663 & $0.141-19.573$ & 0.686 \\
\hline \multicolumn{7}{|l|}{ Smoking status } \\
\hline Non-smoker & 1 & & 0.228 & & & \\
\hline Ex-smoker & 0.684 & $0.131-3.578$ & 0.653 & & & \\
\hline Smoker & 2.778 & $0.734-10.513$ & 0.132 & & & \\
\hline NLR category $>5$ & 4.320 & $1.249-14.498$ & 0.021 & 4.489 & $1.222-16.494$ & 0.024 \\
\hline Albumin $>35 \mathrm{~g} / \mathrm{L}$ & 0.525 & $0.169-1.629$ & 0.265 & & & \\
\hline Preoperative steroid use & 1.510 & $0.488-4.676$ & 0.474 & & & \\
\hline Preoperative immunosuppression & 0.502 & $0.156-1.617$ & 0.248 & & & \\
\hline Emergency surgery & 2.382 & $0.690-8.226$ & 0.170 & & & \\
\hline Sarcopenia & 0.925 & $0.297-2.878$ & 0.893 & & & \\
\hline Myosteatosis & 1.719 & $0.557-5.304$ & 0.346 & & & \\
\hline
\end{tabular}

ASA American Society of Anesthesiologists, BMI Body Mass Index, Cl confidence interval, NLR neutrophil-lymphocyte ratio, OR odds ratio

The impact of sarcopenia and myosteatosis on postoperative outcome has been examined to a greater extent in patients with colorectal cancer; however, there is a substantial variability in study methodology and results. In some reports the presence of sarcopenia and myosteatosis failed to show an association with the occurrence of intra-abdominal leaks or abscesses in patients undergoing colorectal cancer surgical resection, which concurs with the results of the present study $[11,20]$. On the other hand, Huang et al. [35] found an association between sarcopenia and postoperative complications: 10 of 17 patients with sarcopenia had a grade 2 or greater $\mathrm{CCI}$ complication following surgery for colorectal cancer. This cohort therefore included patients with less complex complications in comparison with the present study.

The aetiology of sarcopenia and myosteatosis in cancer, which contribute to the cancer cachexia state, may differ from that of a benign condition, such as IBD, in which the processes causing the altered inflammatory state are more likely to be reversible either medically by immunosuppression or by surgical means. In the setting of cancer, it is generally believed that treating the disease will reduce the pro-inflammatory drive, but this goal is often not achievable [36]. Recent papers have reported that recovery of skeletal muscle volume tends to follow after induction of infliximab in Crohn disease patients [37] or after colectomy in ulcerative colitis patients [38]. In the present study, there was no significant difference in the complication rates between patients with ulcerative colitis and those with Crohn disease.

The classification of patients as affected with sarcopenia has been re-examined in recent years. An initial study by Prado et al. [23] provided cutoff values calculated in a population of obese patients, which may have caused skewing of results when applied to the general population. A follow-up study by Martin et al. [12] provided updated cutoff values with more heterogeneity in the cohort. In the present study, no association was demonstrated between sarcopenia or myosteatosis and postoperative complications when both the cutoff values published by Martin et al. or the lowest gender-specific cutoff were used. 
The advent of low-dose CT has assisted in the assessment of acutely unwell patients with IBD who are at increased risk of high cumulative radiation exposure from diagnostic imaging [39]. This is the first paper to examine the roles of both sarcopenia and myosteatosis, as measured by CT, in patients with IBD with respect to postoperative outcomes. The aetiology of the findings is less clear due to its retrospective design. The inclusion of a preoperative quality of life questionnaire and a short nutritional assessment questionnaire should be considered in a prospective study. Other methods of investigating the role of nutritional assessment of patients with IBD have also been described in the literature. The volumetric assessment of visceral fat has been shown to be associated with postoperative complications and this could be correlated with CT-derived data [40]. The addition of preoperative measurements of muscle function, such as grip strength, could also be considered as direct comparisons with studies of postoperative outcomes in older patients with colorectal cancer are likely to be limited $[9,35]$.

In conclusion, the present study demonstrated an association between myosteatosis and increased hospital stay in addition to an increased 30-day readmission rate for patients with IBD undergoing resection. Given the treatable nature of IBD, there is a potential for sarcopenia and myosteatosis to be assessed in terms of potentially modifiable risk factors for adverse postoperative outcomes and, therefore, for being the target of future therapeutic targets.

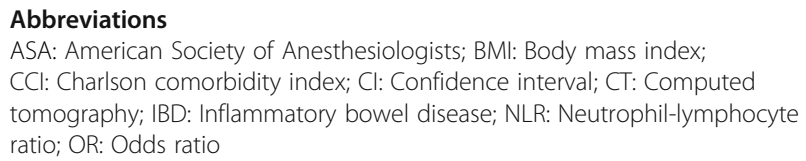

\section{Availability of data and materials}

The datasets used and/or analysed during the current study are available from the corresponding author on reasonable request.

\section{Funding}

The authors declare that this study did not receive any funding.

\begin{abstract}
Authors' contributions
SOB is involved with study design, data acquisition and analysis, manuscript drafting and revising. RGK is involved with data analysis, manuscript drafting and revising. BWC is involved with data analysis, manuscript drafting and revising. MM is involved with study design, data acquisition, manuscript drafting and revising. EA is involved with study design, manuscript drafting and revising. OJOC is involved with study design, data analysis, manuscript drafting and revising. All authors have given final approval to manuscript publication and agree to be accountable for all aspects of the work in ensuring that questions related to the accuracy or integrity of any part of the work are appropriately investigated and resolved.
\end{abstract}

\section{Ethics approval and consent to participate}

Approval for this study was granted by the Clinical Research Ethics Committee of the Cork Teaching Hospitals, Lancaster Hall, 6 Little Hanover Street, Cork, Ireland.

\section{Consent for publication}

Waived by the approval of the retrospective study by the Ethics Committee.

\section{Competing interests}

The authors declare that they have no conflict of interest.

\section{Publisher's Note}

Springer Nature remains neutral with regard to jurisdictional claims in published maps and institutional affiliations.

\section{Author details}

${ }^{1}$ The Hiram C. Polk Jr., MD Department of Surgery, Price Institute of Surgical Research, University of Louisville, Louisville, KY, USA. ${ }^{2}$ Department of Surgery, Cork University Hospital, Cork, Ireland. ${ }^{3}$ Department of Radiology, Cork University Hospital, Cork, Ireland. ${ }^{4}$ Alimentary Pharmabiotic Centre, University College Cork, Cork, Ireland.

Received: 16 July 2018 Accepted: 15 October 2018

Published online: 21 November 2018

\section{References}

1. Burisch J, Jess T, Martinato M, Lakatos PL (2013) The burden of inflammatory bowel disease in Europe. J Crohns Colitis 7:322-237

2. Cosnes J, Gower-Rousseau C, Seksik P, Cortot A (2011) Epidemiology and natural history of inflammatory bowel diseases. Gastroenterology 140: 1785-1794

3. Bernell O, Lapidus A, Hellers G (2000) Risk factors for surgery and recurrence in 907 patients with primary ileocaecal Crohn's disease. Br J Surg 87: 1697-1701

4. Appau KA, Fazio WW, Shen B et al (2008) Use of infliximab within 3 months of ileocolonic resection is associated with adverse postoperative outcomes in Crohn's patients. J Gastrointest Surg 12:1738-1744

5. Kasparek MS, Bruckmeier A, Beigel F et al (2012) Infliximab does not affect postoperative complication rates in Crohn's patients undergoing abdominal surgery. Inflamm Bowel Dis 18:1207-1213

6. da Silva BC, Lyra AC, Rocha R, Santana GO (2014) Epidemiology, demographic characteristics and prognostic predictors of ulcerative colitis. World J Gastroenterol 20:9458-9467

7. Kilcoyne A, Kaplan JL, Gee MS (2016) Inflammatory bowel disease imaging: current practice and future directions. World J Gastroenterol 22:917-932

8. Bahat G, Tufan A, Tufan F et al (2016) Cut-off points to identify sarcopenia according to European Working Group on Sarcopenia in Older People (EWGSOP) definition. Clin Nutr 35:1557-1563

9. Lieffers JR, Bathe OF, Fassbender K, Winget M, Baracos VE (2012) Sarcopenia is associated with postoperative infection and delayed recovery from colorectal cancer resection surgery. Br J Cancer 107:931-936

10. Harimoto N, Shirabe K, Yamashita Yl et al (2013) Sarcopenia as a predictor of prognosis in patients following hepatectomy for hepatocellular carcinoma. Br J Surg 100:1523-1530

11. Reisinger KW, van Vugt $J$, Tegels JJ et al (2015) Functional compromise reflected by sarcopenia, frailty, and nutritional depletion predicts adverse postoperative outcome after colorectal cancer surgery. Ann Surg 261: 345-352

12. Martin L, Birdsell L, Macdonald N et al (2013) Cancer cachexia in the age of obesity: skeletal muscle depletion is a powerful prognostic factor, independent of body mass index. J Clin Oncol 31:1539-1547

13. Montano-Loza AJ, Angulo P, Meza-Junco J et al (2016) Sarcopenic obesity and myosteatosis are associated with higher mortality in patients with cirrhosis. J Cachexia Sarcopenia Muscle 7:126-135

14. Rocha R, Santana GO, Almeida N, Lyra AC (2009) Analysis of fat and muscle mass in patients with inflammatory bowel disease during remission and active phase. Br J Nutr 101:676-679

15. Holt DQ, Strauss BJG, Moore GT (2016) Weight and body composition compartments do not predict therapeutic thiopurine metabolite levels in inflammatory bowel disease. Clin Transl Gastroenterol 7:e199

16. Stidham RW, Waljee AK, Day NM et al (2015) Body fat composition assessment using analytic morphomics predicts infectious complications after bowel resection in Crohn's disease. Inflamm Bowel Dis 21:1306-1313

17. PLOS Medicine Editors (2014) Observational studies: getting clear about transparency. PLoS Med 11:e1001711 
18. Charlson ME, Pompei P, Ales KL, MacKenzie CR (1987) A new method of classifying prognostic comorbidity in longitudinal studies: development and validation. J Chronic Dis 40:373-383

19. Clavien PA, Barkun J, de Oliveira ML et al (2009) The Clavien-Dindo classification of surgical complications: five-year experience. Ann Surg 250: 187-196

20. Malietzis G, Currie AC, Athanasiou T et al (2016) Influence of body composition profile on outcomes following colorectal cancer surgery. $\mathrm{Br}$ J Surg 103:572-580

21. Dello SA, Lodewick TM, van Dam RM et al (2013) Sarcopenia negatively affects preoperative total functional liver volume in patients undergoing liver resection. HPB (Oxford) 15:165-169

22. Mitsiopoulos N, Baumgartner RN, Heymsfield SB, Lyons W, Gallagher D, Ross R (1998) Cadaver validation of skeletal muscle measurement by magnetic resonance imaging and computerized tomography. J Appl Physiol (1985) 85:115-122

23. Prado CM, Lieffers JR, McCargar $L J$ (2008) Prevalence and clinical implications of sarcopenic obesity in patients with solid tumours of the respiratory and gastrointestinal tracts: a population-based study. Lancet Oncol 9:629-635

24. Baumgartner RN, Koehler KM, Gallagher D et al (1998) Epidemiology of sarcopenia among the elderly in New Mexico. Am J Epidemiol 147:755-763

25. van Dijk DPJ, Bakers FCH, Sanduleanu S et al (2018) Myosteatosis predicts survival after surgery for periampullary cancer: a novel method using MRI. HPB (Oxford) 20:715-720

26. Nguyen GC, Munsell M, Harris ML (2008) Nationwide prevalence and prognostic significance of clinically diagnosable protein-calorie malnutrition in hospitalized inflammatory bowel disease patients. Inflamm Bowel Dis 14: 1105-1111

27. Adams DW, Gurwara S, Silver HJ et al (2017) Sarcopenia is common in overweight patients with inflammatory bowel disease and may predict need for surgery. Inflamm Bowel Dis 23:1182-1186

28. Zhang T, Cao L, Cao T et al (2015) Prevalence of sarcopenia and its impact on postoperative outcome in patients with Crohn's disease undergoing bowel resection. JPEN J Parenter Enteral Nutr 41:592-600

29. Schneider SM, Al-Jaouni R, Filippi J et al (2008) Sarcopenia is prevalent in patients with Crohn's disease in clinical remission. Inflamm Bowel Dis 14: 1562-1568

30. Scaldaferri F, Pizzoferrato M, Lopetuso LR et al (2017) Nutrition and IBD: malnutrition and/or sarcopenia? A practical guide. Gastroenterol Res Pract 2017:11

31. Pedersen M, Cromwell J, Nau P (2017) Sarcopenia is a predictor of surgical morbidity in inflammatory bowel disease. Inflamm Bowel Dis 23:1867-1872

32. Razack R, Seidner DL (2007) Nutrition in inflammatory bowel disease. Curr Opin Gastroenterol 23:400-405

33. Mik M, Dziki L, Berut M, Trzcinski R, Dziki A (2018) Neutrophil to lymphocyte ratio and C-reactive protein as two predictive tools of anastomotic leak in colorectal cancer open surgery. Dig Surg 35:77-84

34. Maher MM, O'Connor OJ (2015) Image-guided drainage techniques. In: Belli AM, Lee MJ, Adam A (eds) Grainger and Allison's diagnostic radiology: interventional imaging, Elsevier p 75

35. Huang DD, Wang SL, Zhuang CL et al (2015) Sarcopenia, as defined by low muscle mass, strength and physical performance, predicts complications after surgery for colorectal cancer. Colorectal Dis 17:0256-O264

36. Ní Bhuachalla ÉB, Daly LE, Power DG, Cushen SJ, MacEneaney P, Ryan AM (2018) Computed tomography diagnosed cachexia and sarcopenia in 725 oncology patients: is nutritional screening capturing hidden malnutrition? J Cachexia Sarcopenia Muscle 9:295-305

37. Subramaniam K, Fallon K, Ruut T et al (2015) (2015) Infliximab reverses inflammatory muscle wasting (sarcopenia) in Crohn's disease. Aliment Pharmacolo Ther 41:419-428

38. Zhang T, Ding C, Xie T et al (2017) Skeletal muscle depletion correlates with disease activity in ulcerative colitis and is reversed after colectomy. Clin Nutr 36:1586-1592

39. McLaughlin PD, Murphy KP, Twomey M et al (2016) Pure iterative reconstruction improves image quality in computed tomography of the abdomen and pelvis acquired at substantially reduced radiation doses in patients with active Crohn disease. J Comput Assist Tomogr 40:225-233

40. Connelly TM, Juza RM, Sangster W, Sehgal R, Tappouni RF, Messaris E (2014) Volumetric fat ratio and not body mass index is predictive of ileocolectomy outcomes in Crohn's disease patients. Dig Surg 31:219-224

\section{Submit your manuscript to a SpringerOpen ${ }^{\circ}$ journal and benefit from:}

- Convenient online submission

- Rigorous peer review

- Open access: articles freely available online

High visibility within the field

- Retaining the copyright to your article

Submit your next manuscript at $\boldsymbol{\nabla}$ springeropen.com 